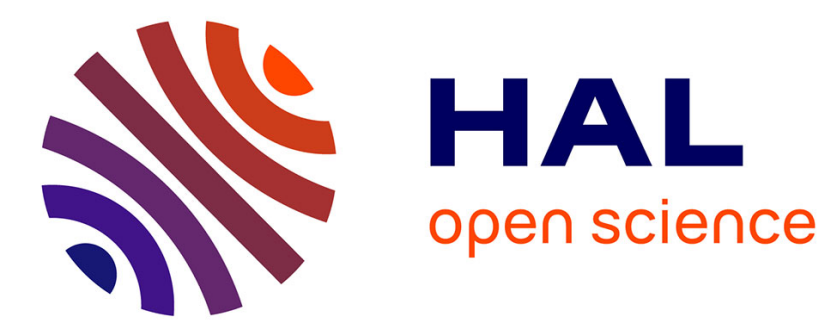

\title{
A fluorous sodium 1 -prolinate derivative as low molecular weight gelator for perfluorocarbons
}

Redouane Beniazza, Natalia Bayo, Damien Jardel, Ruben Rust, Bosi Mao, Thibaut Divoux, Marc Schmutz, Frédéric Castet, Guillaume Raffy, André del Guerzo, et al.

\section{To cite this version:}

Redouane Beniazza, Natalia Bayo, Damien Jardel, Ruben Rust, Bosi Mao, et al.. A fluorous sodium 1 -prolinate derivative as low molecular weight gelator for perfluorocarbons. Chemical Communications, 2020, 56 (61), pp.8655-8658. 10.1039/d0cc02446e . hal-03016439

\section{HAL Id: hal-03016439 \\ https://hal.science/hal-03016439}

Submitted on 20 Nov 2020

HAL is a multi-disciplinary open access archive for the deposit and dissemination of scientific research documents, whether they are published or not. The documents may come from teaching and research institutions in France or abroad, or from public or private research centers.
L'archive ouverte pluridisciplinaire HAL, est destinée au dépôt et à la diffusion de documents scientifiques de niveau recherche, publiés ou non, émanant des établissements d'enseignement et de recherche français ou étrangers, des laboratoires publics ou privés. 


\section{A fluorous sodium L-prolinate derivative as low molecular weight gelator for perfluorocarbons}

Received 00th January 20xx, Accepted 00th January 20xx DOI: $10.1039 / \times 0 \times x 00000 x$

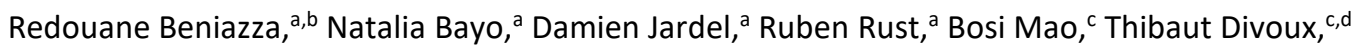
Marc Schmutz, ${ }^{e}$ Frédéric Castet, ${ }^{a}$ Guillaume Raffy, ${ }^{a}$ André Del Guerzo, ${ }^{a}$ Nathan D. McClenaghan, ${ }^{a}$ Thierry Buffeteau and Jean-Marc Vincent ${ }^{\mathrm{a},{ }^{*}}$
The first study dealing with the self-assembly of an $\alpha$-amino acid derivative in perfluorocarbons is reported. Rheology, microscopy, and spectroscopy studies revealed that the fluorous sodium Lprolinate derivative 1 self-assembles in perfluorocarbons to form a three-dimensional network of left-handed nano-helices resulting in solvent gelation. Singlet oxygen lifetime measured in a gel of perfluorodecalin was $\sim 1000$ times longer than in pure water.

Low molecular weight gelators (LMWG) are a unique and important class of chemicals that can self-assemble in solution to form a gel, i.e. an entangled network of fibers trapping solvent molecules. These self-assembled soft materials have great potential in various applications, including cosmetics, catalysis, organic electronics, regenerative medicine, drug delivery and cell culture. ${ }^{1,2}$ Among the various families of LMWGs discovered so far, those based on $\alpha$-amino acids have received considerable attention. ${ }^{2,3}$ Indeed, $\alpha$-amino acids exhibit key attractive features: they are biocompatible, inherently accessible as enantiomerically pure compounds, while they can be easily modified with chemical groups to tune their solubility/aggregation properties, and/or bring new functionalities. To date, $\alpha$-amino acid-based LMWGs have been developed only for aqueous and organic media. Perfluorocarbons (PFCs) are the least polar and least polarisable known fluids. On the $\pi^{*}$ scale of solvent polarity/polarizability, perfluoorooctane has an extremely low value of -0.41 compared to cyclohexane which defines 0 , while water is at 1.09.4 As a consequence PFCs form biphasic systems at room temperature with water and organic solvents, including

\footnotetext{
a. Institut des Sciences Moléculaires, CNRS UMR 5255, Univ. Bordeaux, 33405 Talence, France.

b. Mohammed VI Polytechnic University, UM6P, 43150 Ben Guerir, Morocco.

c. Centre de Recherche Paul Pascal, CNRS UMR 5031 - Université de Bordeaux, 115

Avenue Dr. Schweitzer, 33600 Pessac, France.

d. MultiScale Material Science for Energy and Environment, UMI 3466, CNRS-MIT, 77

Massachusetts Avenue, Cambridge, Massachusetts 02139, USA

e. Université de Strasbourg, CNRS, Institut Charles Sadron UPR22 F67000

Strasbourg, France

Electronic Supplementary Information (ESI) available: [details of any supplementary information available should be included herel. See DOI: 10.1039/x0xx00000x
}

alkanes. PFCs are non-toxic biocompatible liquids, nonflammable, chemically inert and dissolve gases in large amounts including $\mathrm{O}_{2}$ and $\mathrm{CO}_{2} \cdot{ }^{5}$ Therefore, PFC gels/emulsions ${ }^{6}$ have strong potential for bioapplications requiring oxygen delivery such as blood substitutes, ${ }^{7}$ wound-healing treatments, ${ }^{8}$ photodynamic therapy (PDT), ${ }^{9}$ or cell culture. ${ }^{10}$ Also, PFCs are the liquids which exhibit the lowest intermolecular cohesiveness, a key property of high performance lubricants. On the other hand, such low cohesiveness makes PFCs very challenging to gelate. To date, only a few LMWGs of PFCs have been described (Fig. 1). ${ }^{11}$ These gelators were shown to gelate PFCs including perfluorodecalin (PFD), $n$-perfluorooctane, perfluorotributylamine (FC-43), perfluorotripentylamine (FC70), bromoperfluorooctane, or the $1,1,1,2,2,4,4,5,5,5$ decafluoropentan-3-one. From previous results it thus emerged that PFC gels of an $\alpha$-amino acid-derived LMWG might be of great value for biomedical applications such as PDT. Here we report the first example of an $\alpha$-amino acid-based LMWG for PFCs. In this preliminary account, the synthesis of the fluorous sodium L-prolinate 1 (Fig. 1), its gelating properties and the characterization of the PFC gels using rheology, microscopy, vibrational circular dichroism and modelling studies, are described. Preliminary data on photosensitized singlet oxygen generation in a gel of perfluorodecalin are also reported.

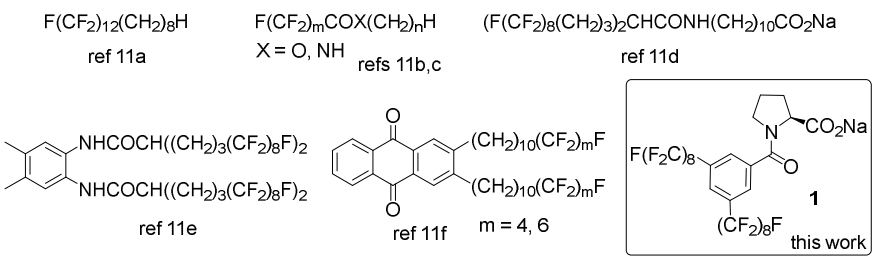

Fig 1 Molecular structures of LMWGs for perfluorocarbons.

Fluorous sodium L-prolinate 1 was prepared in 3 steps from 3,5diiodobenzoic acid and L-proline methyl ester (see ESI, Fig. S1). Solubility tests showed that $\mathbf{1}$ is insoluble at room temperature in water, organic solvents and PFCs. Moreover, gelation tests revealed that 1 was unable to gelate water or any of the organic 
solvents tested (see ESI). Conversely, $\mathbf{1}$ is an excellent gelator for PFCs. The gels were obtained by dispersing 1 by sonication ( $0.5 \mathrm{~mL}$ of solvent in $2 \mathrm{~mL}$ vials), followed by rapid heating to the solvent boiling point to obtain a transparent solution, before cooling down to $20^{\circ} \mathrm{C}$. Remarkably, fully transparent gels (Fig. 2) for perfluoromethylcyclohexane (PFMC, bp $76{ }^{\circ} \mathrm{C}$, d 1.79 $\mathrm{g} / \mathrm{cm}^{3}$ ), perfluorodecalin (PFD, bp $142{ }^{\circ} \mathrm{C}, \mathrm{d} 1.92 \mathrm{~g} / \mathrm{cm}^{3}$ ) and perfluorotripentylamine (FC-70, bp $215{ }^{\circ} \mathrm{C}$, d $1.93 \mathrm{~g} / \mathrm{cm}^{3}$ ) containing as little as $0.5-0.6 \mathrm{wt} \%$ of 1 for PFD and PFMC, and 1 wt\% for FC-70, were obtained. These weight fractions correspond to the lowest gelation concentrations of $9.5 \mathrm{mM}$ and $17 \mathrm{mM}$, respectively. Gels of $n$-perfluoorooctane (bp 103$104{ }^{\circ} \mathrm{C}, \mathrm{d} 1.77 \mathrm{~g} / \mathrm{cm}^{3}$ ) were successfully prepared as well, but syneresis occurred within minutes after gelation. Interestingly, the hydrofluoroether HFE-7500 could also be gelated by 1 with a minimum gelling concentration of $9.5 \mathrm{mM}(0.56 \mathrm{wt} \%)$ yielding a fully transparent gel (Fig. 2).

The linear viscoelastic properties of perfluorodecalin gels were characterized using a parallel-plate geometry connected to a stress-controlled rheometer. The sample temperature is controlled by a Peltier module placed under the bottom plate. The liquid PFD solutions were introduced at a temperature of about $120^{\circ} \mathrm{C}$ in the geometry pre-heated at $80^{\circ} \mathrm{C}$, which is then sealed with a layer of Sunflower seed oil to prevent evaporation over the duration of the experiment. The gelation was induced by a decreasing ramp of temperature from $80^{\circ} \mathrm{C}$ down to $20^{\circ} \mathrm{C}$ (Fig.3a), while the viscoelastic properties were monitored by small amplitude oscillations. As illustrated in Fig. 3b for a sample containing $3 \mathrm{wt} \%$ of $\mathbf{1}$, the elastic modulus $\left(G^{\prime}\right)$ and the viscous modulus $\left(G^{\prime \prime}\right)$ increase during the temperature ramp before reaching steady-state values after 20 min verifying $G_{0}^{\prime} \gg G^{\prime \prime}{ }_{0}$, which means that the sample, initially liquid, turned into a soft solid. Beyond the gelation point associated with the crossing point of $G^{\prime}$ and $G^{\prime \prime}$ at a temperature higher than $70{ }^{\circ} \mathrm{C}$, the sample experiences a vertical contraction, as evidenced by the decrease of the gap width separating the two plates (see grey symbols in Fig. 3b). This contraction is strongly reminiscent of that observed during the gelation of solutions of polysaccharides such as agarose and carrageenan, ${ }^{12}$ although here the contraction takes place after the gelation point. Repeating these rheological measurements on samples prepared with different gelling contents $c$ shows that the terminal elastic modulus $G_{0}^{\prime}$ increases as a power law of c (Fig. 3c), which is a common feature of polymer gels. ${ }^{13}$ Finally, the sample contraction seems to increase for increasing amount of gelling agent (Fig. 3d).

As gelator $\mathbf{1}$ is chiral, we used vibrational circular dichroism (VCD) to characterize the PFC gels. The infrared (IR) and VCD spectra measured for $1 \mathrm{wt} \%$ of 1 in PFD are reported in Fig. 4 in the $1700-1550 \mathrm{~cm}^{-1}$ spectral range, since no VCD contribution appears at lower wavenumbers (Fig. S2). The rotation of the cell around the light beam axis gave no change in the VCD spectra (Fig. S3), revealing no linear dichroism contribution. A strong positive couplet is observed around $1660 \mathrm{~cm}^{-1}$ with negative and positive components at 1664 and $1658 \mathrm{~cm}^{-1}$, respectively, assigned to the stretching vibration $(v C=0)$ of the amide carbonyl group located at $1661 \mathrm{~cm}^{-1}$ in the IR spectrum (See the calculated IR spectra Fig. S10). This couplet arises from the coupling of adjacent carbonyl groups (transition dipole coupling

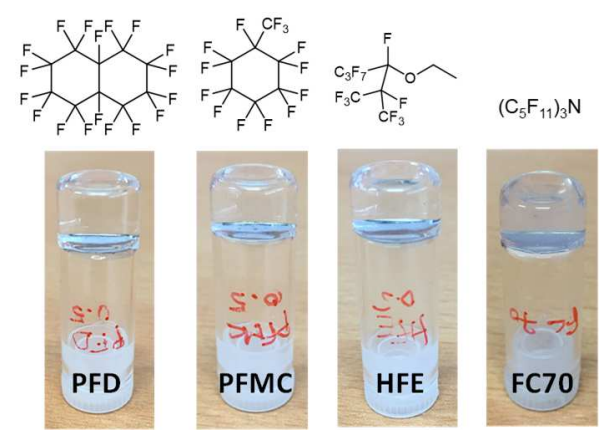

Fig. 2 Photos of PFD, PFMC and HFE-7500 gels (inverted test tubes) at $9.5 \mathrm{mM}$, and a FC70 gel at $17 \mathrm{mM}$.
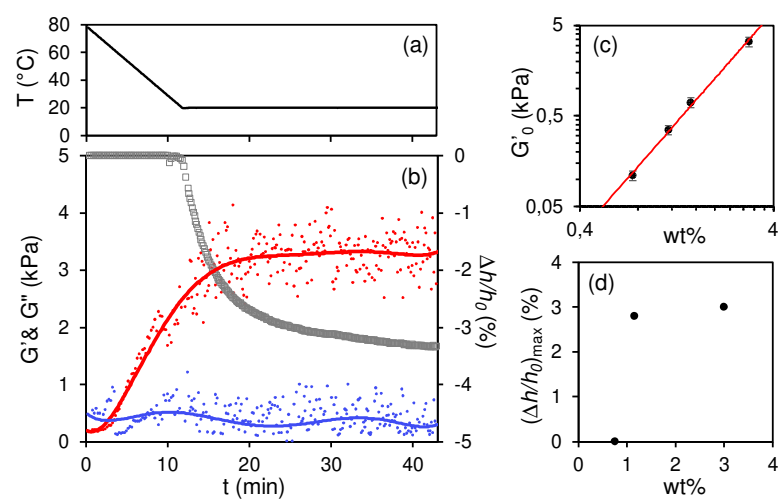

Fig. 3 (a) Temperature ramp imposed on the sample to induce gelation. The cooling rate is $5^{\circ} \mathrm{C} / \mathrm{min}$. (b) Evolution of the elastic ( $G$,' in red) and viscous modulus ( $G$," in blue) measured by oscillations of small amplitude (strain $\gamma=0.01 \%$ ) during the formation of a perfluorodecalin gel composed of $3 \mathrm{wt} \%$ of 1 . The continuous lines correspond to a box average of the data. The experiment is performed at constant normal force $\left(F_{N}=0 \mathrm{~N}\right)$, while the gap width (initial value $h_{0}$ ) is free to adapt to maintain such a constrain. The relative change in the gap width is plotted as grey open squares (right axis). The sample contracts by about $3 \%$ over the gelation transition. (c) Evolution of the terminal values of the elastic modulus $G^{\prime}{ }_{0}$ with the amount of 1 reported in logarithmic scales. The red line corresponds to the best power-law fit of the data: $G_{0}^{\prime}=(0.26 \pm 0.01) \times$ $c^{(2.28 \pm 0.05)}$. The error bar was determined by repeating three times the experiment on the $3 \%$ sample. (d) Maximal relative gap decrease $\left(\Delta h / h_{0}\right)_{\max }$ during gelation of samples with different contents in $\mathbf{1}$.

model) in the helical supramolecular structure. ${ }^{14}$ Furthermore, the intensity of this couplet is related to the number of molecules in the supramolecular structure. ${ }^{15}$ The anisotropic ratio (also called $\mathrm{g}$ factor) ${ }^{16}$ is equal to $0.0064 \pm 0.0001$, which is in the range of values obtained for amyloid fibrils, ${ }^{17,18}$ and ten times lower than values obtained for fluorinated gelators based on 1,2-diaminocyclohexane. ${ }^{19}$ Three other VCD bands of weak and negative intensities are observed at 1631, 1623 and 1614 $\mathrm{cm}^{-1}$, related to the antisymmetric stretching vibration $\left(\mathrm{v}_{\mathrm{a}} \mathrm{COO}^{-}\right)$ of the carboxylate groups and coupled modes with the amide $v \mathrm{C}=\mathrm{O}$ vibration (Fig. S10). The $\mathrm{g}$ factor of the $\mathrm{v}_{\mathrm{a}} \mathrm{COO}^{-}$band $(-2.4$ $\left.\times 10^{-4}\right)$ is significantly lower than the one of the amide carbonyl band. Information about the chirality of perfluoroalkyl chains between 1300 and $1100 \mathrm{~cm}^{-1}$ is not possible in our study due to the interference associated with the strong absorptions of the PFD solvent in this region. Finally, replacing the sodium counterion with potassium results in a small decrease of the $g$ 
factor for the couplet related to the carbonyl band, with a value equal to $0.0058 \pm 0.0002$ (Fig. 4).

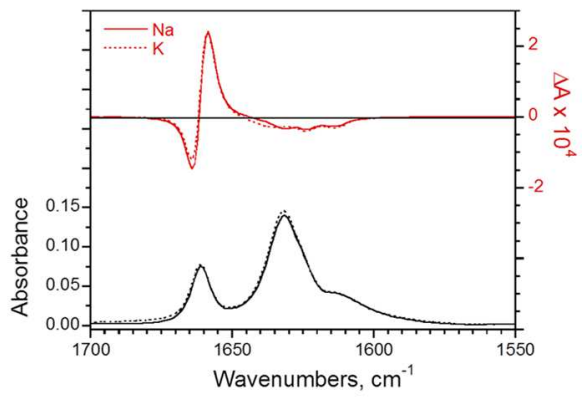

Fig. $4 \mathrm{VCD}$ (top) and IR (bottom) spectra measured for $1 \mathrm{wt} \%$ perfluorodecalin gels of 1 (solid line), and fluorous potassium L-prolinate derivative (dotted line) in PFD solvent.

To get more insights on the native 3D fibrillar network of PFC gels, Cryo-Scanning Electron Microscopy (cryo-SEM) and Atomic Force Microscopy (AFM) were used (Fig. 5). First, we emphasize that we could not observe fibers deposited on a surface that are devoid of solvent. This is because the fluorous fibers do not adhere on the carbon grid or the glass coverslip on which they are deposited, but migrate with the solvent front upon evaporation, to reach a point where their density becomes too high to allow their observation. Consequently, attempts to exploit classical high-resolution TEM or SEM techniques failed. On the contrary, the microstructure of a perfluorodecalin gel was obtained by cryo-SEM. The sample was prepared by fracturing the upper surface of a quickly frozen piece of gel followed by short sublimation of the solvent $\left(2 \mathrm{~min}\right.$ at $-90^{\circ} \mathrm{C}$ ) before metallization with a thin layer of platinum. Fig. $5 \mathrm{a}$ and Fig. S5 reveal that in the perfluorodecalin solvent the gel is composed of a dense network of nanofibrils, the average diameter of which is about $10 \mathrm{~nm}$. Higher-resolution images were obtained by AFM, in particular using alternative contact mode phase image, which provides images of the fibrils that are still surrounded by the solvent (Fig. 5b, Fig. S6-S8). These images unambiguously show the presence of nano-helices that are all left-handed (M), whose average width is $10.6 \pm 2.4 \mathrm{~nm}$, in agreement with the width observed by cryo-SEM, while the average pitch is $13.1 \pm 4.1 \mathrm{~nm}$ (Fig. S9). Taken together, the IR, VCD and microscopy studies reveal a gelation mechanism in which the fluorous proline $\mathbf{1}$ self-assembles in PFCs into a dense network of thin $M$ nano-helices leading to very effective formation of gels.

When considering the possible mechanism of the molecular self-assembly leading to the fiber formation, previous studies on LMWGs have revealed that the carboxylate-sodium interaction was a key driving force in the gelation processes. ${ }^{3 a, 11 d, 20}$ The carboxylic acid of 1, which exhibits improved solubility compared to $\mathbf{1}$, fails to gelate the PFCs but leads to the formation of crystalline materials instead. Comparison of the experimental IR spectrum of the PFD gel of 1 with the calculated spectra for four structures of $\mathbf{1}$ having various carboxylate/ $\mathrm{Na}^{+}$ratios and binding modes (structures $\mathrm{A}$ $D$ in Fig. S10), led us to propose structure $D$ as the most likely. In this structure, each carboxylate is coordinated to three sodium ions by both non-bridging bidentate and bridging bidentate coordination modes, with the oxygen atom of the amide group also binding one sodium. Upon self-assembly, such arrangement should favour the formation of coordination polymers that could drive the elongation process necessary to form fibers. Notably, such carboxylate/sodium binding modes are found in the X-ray structures of compounds structurally related to 1 , namely, the antihypertensive drug Fosinopril Sodium $2,,^{21}$ and the sodium salt of the $(R)$-Phenylalanine functionalized norbornene $3,^{3 a}$ a LMWG for organic solvents (Fig. S11a). In the crystal, these compounds are assembled into coordination polymers forming 1D infinite double-strands for $\mathbf{2}$ (Fig. S11b), ${ }^{21}$ or helical columns for $\mathbf{3 .}^{3 a}$
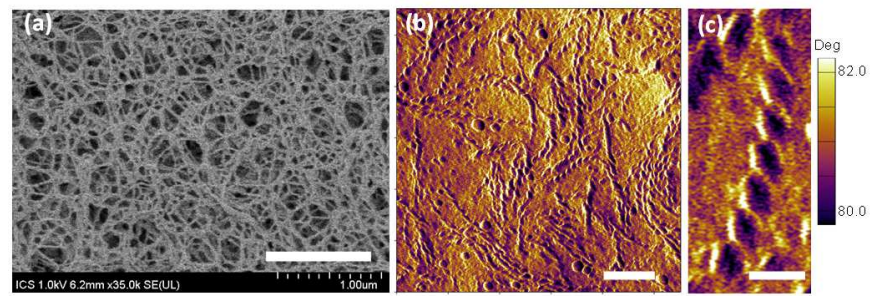

Fig. 5 (a) Cryo-SEM image (scale bar $1 \mu \mathrm{m}$ ) of a perfluorodecalin gel of $\mathbf{1}(0.5 \mathrm{wt} \%$, see the text and ESI for details on sample preparation). (b) AFM phase image (scale bar 100 $\mathrm{nm}$ ) of a perfluorodecalin gel of $\mathbf{1}(1 \mathrm{wt} \%$ ) recorded during solvent evaporation (See ESI for experimental details). (c) Zoom on a helix (scale bar $25 \mathrm{~nm}$ ).

Finally, having in mind the potential of PFCs gels for application in topical PDT we conducted, for the first time, studies on the photogeneration of singlet oxygen in a PFC gel. Gels of perfluorodecalin containing the highly fluorophilic porphyrin $4^{9 a, 22}$ as photosensitizer $\left(6.8 \times 10^{-5} \mathrm{M}\right)$ were prepared (Fig. S12), and the amount and lifetime of ${ }^{1} \mathrm{O}_{2}$ generated by photoirradiation by irradiation at $532 \mathrm{~nm}$ were evaluated. We find that for a $0.6 \mathrm{wt} \% \mathrm{PFC}$ gel, the amount of ${ }^{1} \mathrm{O}_{2}$ luminescence detected $\left(\lambda_{\max }=1270 \mathrm{~nm}\right)$ is about 4.5 lower than that of the PFD porphyrin solution, as shown in Fig. 6 . This result is mirrored by the ${ }^{1} \mathrm{O}_{2}$ lifetime, which decreases from $17.3 \mathrm{~ms}$ in solution to $3.7 \mathrm{~ms}$ in the gel, i.e. by a factor of about 4.7. A similar radiative rate constant can, therefore, be inferred in solution and inside the gel, while non-radiative deexcitation processes are enhanced which is consistent with modest dynamic quenching of ${ }^{1} \mathrm{O}_{2}$ by interaction with 1 . Also, a SternVolmer type analysis (Table S1, Fig. S13) shows a linear dependence of singlet oxygen luminescence quenching in gels with increasing concentrations of gelator molecule (quencher) consistent with dynamic quenching, rather than coconfinement-enhanced quenching. Despite that, the long ${ }^{1} \mathrm{O}_{2}$ lifetime (which determines its effective diffusion distance) of $3.7 \mathrm{~ms}$ measured in the $0.6 \mathrm{wt} \%$ PFD gel is still much higher than those measured in acetonitrile $(54.4 \mu \mathrm{s})$, benzene $(26.7 \mu \mathrm{s})$ or water $(4 \mu \mathrm{s}) .{ }^{23,24}$

To conclude, we have shown that the fluorous sodium Lprolinate 1 self-assembles in perfluorocarbons to form a threedimensional network of left-handed nano-helices resulting in the formation of transparent PFC gels. Combined IR and modelling studies suggest that the fiber elongation process 
originates from the formation of a coordination polymer. Data showing the long singlet oxygen lifetime in PFC gels are also reported. These results bode well for application of such transparent biocompatible PFC gels for PDT, gels which should facilitate topical application on skin, while favouring woundhealing and effective ${ }^{1} \mathrm{O}_{2}$ delivery.

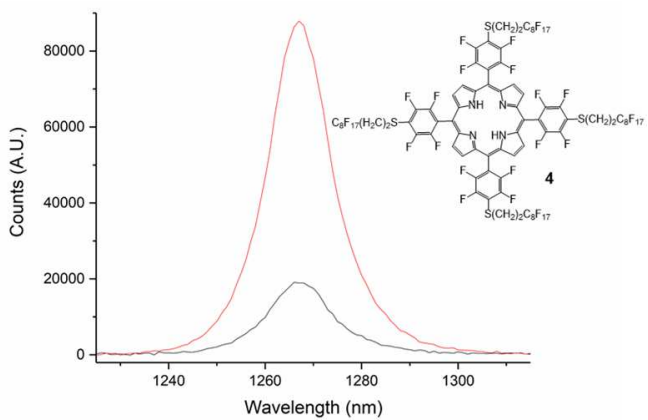

Fig. 6 Singlet oxygen phosphorescence from a perfluorodecalin solution (red line) of porphyrin photosensitizer $4\left(6.8 \times 10^{-5} \mathrm{M}, \lambda_{\mathrm{ex}}=532 \mathrm{~nm}\right)$ and corresponding opticallytransparent gel (black line) comprising gelator 1 (0.6 wt\%).

\section{Conflicts of interest}

There are no conflicts to declare.

\section{References}

1 Selected reviews: (a) R. G. Weiss, J. Am Chem. Soc., 2014, 136, 7519-7530; (b) M. George, R. G. Weiss, Acc. Chem. Res., 2006, 39, 489-497; (c) E. R. Draper, D. J. Adams, Chem., 2017 3, 390-410; (d) P. Terech, R. G. Weiss, Chem. Rev., 1997, 97, 3133-3159; (e) J. van Esch, B. L. Feringa, Angew. Chem. Int. Ed., 2000, 39, 2263-2354; (f) N. M. Sangeetha, U. Maitra, Chem. Soc. Rev., 2005, 34, 821-836; (g) A. R. Hirst, B. Escuder, J. F. Miravet, D. K. Smith, Angew. Chem. Int. Ed., 2008, 47, 8002-8018; (h) L. A. Estroff, A. D. Hamilton, Chem. Rev., 2004, 104, 1201-1217; (i) Y. Lan, M. G. Corradini, R. G. Weiss, S. R. Raghavan, M. A. Rogers, Chem. Soc. Rev., 2015, 44, 6035-6058.

2 Reviews: (a) A. Dasgupta, J. H. Mondal, D. Das, RSC Adv. 2013, 3, 9117-9149; (b) J. B. Matson, S. I. Stupp, Chem. Commun., 2012, 48, 26-33.

3 Selected examples of $\alpha$-amino acids/peptide-based LMWGs: (a) J. R. Engstrom, A. J. Savyasachi, M. Parhizkar, A. Sutti, C. S. Hawes, J. M. White, T. Gunnlaugsson, F. M. Pfeffer, Chem. Sci., 2018, 9, 5233-5241; (b) S. Basak, N. Nandi, S. Paul, I. A. Hamley, A. Banerjee, Chem. Commun. 2017, 53, 5910-5913; (c) D. Yuan, X. Du, J. Shi, N. Zhou, J. Zhou, B. Xu, Angew. Chem. Int. Ed., 2015, 54, 5705-5708; (d) F. RodriguezLlansola, B. Escuder, J. F. Miravet, J. Am. Chem. Soc., 2009, 131, 11478-11484; (e) F. Wang; C.-L. Feng, Angew. Chem. Int. Ed., 2018, 57, 5655-5659; (f) C. Y. Goh, T. Becker, D. H. Brown, B. W. Skelton, F. Jones, M. Mocerino, M. I. Ogden, Chem. Commun., 2011, 47, 6057-6059; (g) A. R. Hirst, I. A. Coates, T. R. Boucheteau, J. F. Miravet, B. Escuder, V. Castalleto, I. W. Hamley, D. K. Smith, J. Am. Chem. Soc., 2008, 130, 9113-9121; (h) S. Basak, I. Singh, A. Ferranco, J. Syed, H.-B. Kraatz, Angew. Chem. Int. Ed., 2017, 56, 13288-13292; (i) J. Rodon Fores, M. Criado-Gonzales, A. Chaumont, A. Carvalho, C. Blanck, M. Schmutz, C. A. Serra, F. Boulmedais, P. Schaaf, L. Jierry, Angew. Chem. Int. Ed., 2019, 58, 1881718822; (j) P. W. J. M. Frederix, G. G. Scott, Y. M. Abul-Haija,
D. Kalafatovic, C. G. Pappas, N. Javid, N. T. Hunt, R. V. Ulijn, T. Tuttle, Nat. Chem., 2015, 7, 30-37; (k) A. Raghavanpillai, V. A. Franco, W. E. Meredith, J. Fluorine Chem., 2012, 135, 187194; (I) A. Raghavanpillai, V. A. Franco, Appl. Sci., 2012, 2, 175-191; (m) C. Shi, Z. Huang, S. Kilic, J. Xu, R. M. Enick, E. J. Beckman, A. J. Carr, R. E. Melendez, A. D. Hamilton, Science, 1999, 286, 1540-1543.

4 a) M. J. Kamlet, J. L. Abboud, R. W. Taft, J. Am. Chem. Soc. 1977, 99, 6027-6038; b) J. E. Brady, P. E. Carr, Anal. Chem. 1982, 54, 1751-1757.

5 J. A. Gladysz, C. Emnet, Fluorous solvents and related media, in: J. A. Gladysz, D. P. Curran, I. T. Horváth (Eds.), Handbook of Fluorous Chemistry, Wiley-VCH: Weinheim Germany, 2004, pp 11-23.

6 a) M. P. Krafft, Fluorocarbon gels, in: S. Magdassi, E. Touitou (Eds.), Novel Cosmetic Delivery Systems, Marcel Dekker, New York, 1998, pp 195-219.

7 J. G. Riess Artif. Cells Blood Substit. Immobil. Biotechnol., 2006, 34, 567-580.

8 J. Lie, Y.-P. Zhang, M. Zarei, L. Zhu, J. O. Sierra, P. M. Mertz, S. C. Davis, Burns, 2015, 41, 1049-1057.

9 (a) R. A. Day, D. A. Estabrook, J. K. Logan, E. M. Sletten, Chem. Commun., 2017, 53, 13043-13046; (b) Y. Cheng, H. Cheng, C. Jiang, X. Qiu, K. Wang, W. Huan, A Yuan, J. Wu, Y. Hu, Nat Commun, 2015, 6, 8785.

10 H. Miyajima, M. C. Kasuya, K. Hatanaka, J. Fluorine Chem., 2014, 163, 46-49.

11 (a) J, Höpken, C. Pugh, W. Richtering, M. Möller, Makromol. Chem., 1988, 189, 911-925; (b) M. George, S. L. Snyder, P. Terech, R. G. Weiss, Langmuir, 2005, 21, 9970-9977; (c) M. George, S. L. Snyder, P. Terech, C. J. Glinka, R. G. Weiss, J. Am. Chem. Soc., 2003, 125, 10275-10283; (d) J. Gan, M. El Bakkari, C. Belin, C. Margottin, P. Godard, J.-L. Pozzo, J.-M. Vincent, Chem. Commun., 2009, 5133-5134; (e) J. Loiseau, M. Lescanne, A. Colin, F. Fages, J.-B. Verlhac, J.-M. Vincent, Tetrahedron, 2002, 58, 4049-4052; (f) H. Miyajima, M. C. Z. Kasuya, K. Hatanaka, J. Fluorine. Chem., 2019, 222-223, 2430.

12 B. Mao, T. Divoux, P. Snabre, J. Rheol., 2016, 60, 473-489.

13 M. Djabourov, K. Nishinari and S.B. Ross-Murphy, Physical gels from biological and synthetic polymers, Cambridge University press (2013).

14 I. Tinoco, Radiation Research, 1963, 20, 133-139.

15 H. Torii, H. Sato, Phys. Chem. Chem. Phys., 2018, 20, $14992-$ 14996.

16 The anisotropic ratio is calculated as the intensity difference between the positive and negative components of the VCD couplet divided by the intensity of the IR band.

17 D. Kurouski, X. Lu, L. Popova, W. Wan, M. Shanmugasundaram, G. Stubbs, R. K. Dukor, I. K. Lednev, L. A. Nafie, J. Am. Chem. Soc., 2014, 136, 2302-2312.

18 B. Martial, T. Lefèvre, T. Buffeteau, M. Auger, ACS Nano, 2019, 13, 3232-3242.

19 H. Sato, T. Yajima, A. Yamagishi, Chem. Commun., 2011, 47, 3736-3738.

20 (a) G. Mieden-Gundert, L. Klein, M. Fischer, F. Vögtle, K. Heuzé, J.-L. Pozzo, M. Vallier, F. Fages, Angew. Chem. Int. Ed., 2001, 40, 3164-3166; (b) M. Suzuki, M. Yumuto, M. Kimura, H. Shirai, K. Hanabusa, Helv. Chim. Acta, 2004, 87, 1-10.

21 N. G. Anderson, D. A. Lust, K. A. Colapret, J. H. Simpson, M. F. Malley, J. Z. Gougoutas, J. Org. Chem., 1996, 61, 7955-7958.

22 J. F. B. Hall, X. Han, M. Poliakoff, R. A. Bourne, M. W. George, Chem. Commun., 2012, 48, 3073-3075.

23 P. R. Ogilby, C. S. Foote, J. Am. Chem. Soc., 1983, 105, 34233430.

24 R. Corrêa da Costa, T. Buffeteau, A. Del Guerzo, N. D. McClenaghan, J.-M. Vincent, Chem. Commun., 2011, 47, 8250-8252. 